Institutionenökonomie und

Neuer Institutionalismus 
Schriftenreihe

Interdisziplinäre Organisationsund Verwaltungsforschung 2

Herausgeberbeirat

Günther Ortmann

Wolfgang Seibel

Arndt Sorge

Jörg Sydow

Klaus Türk 
Thomas Edeling/Werner Jann/Dieter Wagner (Hrsg.)

\section{Institutionenökonomie und \\ Neuer Institutionalismus}

Überlegungen zur Organisationstheorie 
Gedruckt auf säurefreiem und altersbeständigem Papier.

ISBN 978-3-8100-2122-9

ISBN 978-3-322-95071-0 (eBook)

DOI 10.1007/978-3-322-95071-0

(C) 1999 Springer Fachmedien Wiesbaden

Ursprünglich erschie bei Leske + Budrich, Opladen 1999

Das Werk einschließlich aller seiner Teile ist urheberrechtlich geschützt. Jede Verwertung außerhalb der engen Grenzen des Urheberrechtsgesetzes ist ohne Zustimmung des Verlages unzulässig und strafbar. Das gilt insbesondere für Vervielfältigungen, Übersetzungen, Mikroverfilmungen und die Einspeicherung und Verarbeitung in elektronischen Systemen. 


\section{Inhaltsverzeichnis}

\section{Thomas Edeling}

Einführung: Der Neue Institutionalismus in Ökonomie und Soziologie...

Gerhard Göhler, Rainer Kühn

Institutionenökonomie, Neo-Institutionalismus und die Theorie

politischer Institutionen

Klaus Türk

Organisation und moderne Gesellschaft.

Einige theoretische Bausteine

\section{Veronika Tacke}

Beobachtungen der Wirtschaftsorganisation.

Eine systemtheoretische Rekonstruktion institutionenökonomischer und neo-institutionalistischer Argumente in der Organisationsforschung .......

Erhard Stölting

Informelle Machtbildung und Leitideen im institutionellen Wandel

Birgitta Wolff

Zum methodischen Status von Verhaltensannahmen in der

Neuen Institutionenökonomik

Günther Schanz

Exklusivrechte auf die ökonomische Perspektive?

Konfrontation neoinstitutionalistischer Anmaßungen mit verhaltenstheoretischen Argumenten 
Arndt Sorge/Ronald Batenburg

Vertical Integration into Electronics: Transaction Costs and

Organization Domain

Detlev Hummel

Neoinstitutionalismus in der Finanzierungs- und Banktheorie -

Entwicklungsaspekte und Anwendungsfelder der

New Institutional Economics

Ludwig Theuvsen

Transaktionskostentheorie: Anwendungen auf

Non-Profit-Organisationen

Autorenverzeichnis. 